facilidad; tiene algunas erratas, pero de muy poca importancia (por ejemplo, utiliza la palabra "neoricardiana", evidentemente debe sustituirse por "neorricardiana"). En resumen, un libro valioso que no deja indiferente. [ $M^{a}$ del Carmen López MARTíN]

\title{
Educación y Psicología
}

Global University Network for InNOVAtion (2009) La educación superior en tiempos de cambio. Nuevas dinámicas para la responsabilidad social, Madrid, MundiPrensa, 222 pp.

La Global University Network for Innovation (GUNI) es una red creada en 1999 por la UNESCO, la Universidad de Naciones Unidas y la Universitat Politècnica de Catalunya. Actualmente la conforman casi 170 miembros de más de 60 países, incluye las cátedras UNESCO de educación superior, instituciones de educación superior, centros de investigación y redes relacionadas con la innovación y el compromiso social de la educación superior. Se creó a raíz de la Conferencia Mundial sobre Educación Superior de la UNESCO de 1998, con el objetivo de contribuir a la reforma e innovación de políticas de educación superior en todo el mundo desde una perspectiva de servicio público, pertinencia y responsabilidad social.

Dentro de la serie publicada por GUNI sobre el compromiso social de las universidades se encuentran los tres volúmenes del informe La Educación Superior en el Mundo:

- La educación superior en el mundo 2006: la financiación de las universidades.

- La educación superior en el mundo 2007: acreditación para la garantía de calidad: ¿qué está en juego?

- La educación superior en el mundo 3: nuevos retos y roles emergentes para el desarrollo humano y social.

La educación superior en tiempos de cambio es una síntesis de estos tres volúmenes y fue encargado por la UNESCO con motivo de la celebración de la Conferencia Mundial sobre Educación Superior 2009.

En el presente informe han colaborado 70 autores de 34 países, que analizan los retos actuales y futuros a los que se enfrentan las instituciones de educación superior en el contexto de la globalización. En esta publicación se hace un resumen de los temas globales de cada uno de los artículos incluidos en el informe original. A lo largo de la publicación se exponen 24 "buenas prácticas" que describen programas o proyectos que están llevando a cabo diferentes instituciones de educación superior o investigación.

Esta publicación se estructura en cinco partes:

- La primera parte es la introducción y se titula "Nuevas dinámicas para la 
responsabilidad social". Analiza el rol de la educación y propone un camino de acción para pasar de una educación al servicio del mundo económico a una educación motor del desarrollo humano sostenible.

- La segunda parte, "Síntesis de la educación superior en el mundo 3. Educación superior: nuevos retos y roles emergentes para el desarrollo humano y social". En ella se plantea el contexto que rodea la educación superior en el sigloXXI, el entorno en el que trabaja la universidad. Se describen las funciones que tienen las instituciones de educación superior actualmente, y se proponen nuevas perspectivas con respecto al papel que tienen para afrontar los retos del desarrollo humano y social

- La tercera parte "Síntesis de la educación superior en el mundo 2006. La financiación de las universidades", aborda la financiación de la educa-

\section{Ética}

Bartlett, Enric R. y BardaII, $M^{a}$ Dolores, (Coordinadores) (2009) 1957-2007. 50 años de derechos humanos y Europa, Barcelona, FAES - ESADE, Facultad de Derecho - Bosch (Seminario Permanente de Derechos Humanos Antonio Marzal - $13^{\mathrm{a}}$ sesión), 174 pp.

El hecho de acometer un cualificado grupo de especialistas un análisis de los Derechos Humanos y Europa en un periodo de cincuenta años, el que abarca desde 1957 ción superior en el ámbito global, los posibles medios de financiación y sus implicaciones políticas.

- La cuarta parte, "Síntesis de la educación superior en el mundo 2007. Acreditación para la garantía de la calidad, ¿Qué está en juego?" estudia aspectos sobre la acreditación y la garantía de calidad que proporcionan información sobre la situación actual y también permiten conocer el proceso de contribución de la educación superior a la sociedad.

- La quinta parte es un "Anexo estadístico"

En resumen, se trata de un tema de mucha actualidad, sobre todo, en el contexto del proceso de Bolonia y, por ello, de un libro de interés para los universitarios, tanto docentes como los administradores y gestores de los centros. [Ana $M^{a}$ SÁNCHEZ TORRES]

-año en el que tiene lugar la firma por seis Estados europeos, del Tratado de Roma, origen de la presente Unión Europea- a 2007 -año en el que son veintisiete el número de Estados que la integran- y hacerlo con la seriedad y el rigor con el que lo llevan a cabo en el libro que comentamos, es sin duda, de agradecer.

No es frecuente encontrar obras como esta, en la que desde distintos punto de vista, pero bajo un denominador común, el respeto a la 